Article

\title{
Design and Simulation of a Wireless SAW-Pirani Sensor with Extended Range and Sensitivity
}

\author{
Sofia Toto ${ }^{1}$, Pascal Nicolay ${ }^{2}{ }^{(D)}$, Gian Luca Morini ${ }^{3}{ }^{\circledR}$, Michael Rapp ${ }^{1}$, Jan G. Korvink ${ }^{1}(\mathbb{D}$ and \\ Juergen J. Brandner 1,*(D) \\ 1 Institute of Microstructure Technology, Karlsruhe Institute of Technology, Hermann-von-Helmholtz-Platz 1, \\ 76344 Eggenstein-Leopoldshafen, Germany; sofia.toto@kit.edu (S.T.); michael.rapp@kit.edu (M.R.); \\ jan.korvink@kit.edu (J.G.K.) \\ 2 Carinthia Institute for Smart Materials and Manufacturing Technologies (CiSMAT), Carinthia University of \\ Applied Sciences, 9524 Villach/St. Magdalen, Austria; p.nicolay@fh-kaernten.at \\ 3 Dipartimento di Ingegneria Industriale, Alma Mater Studiorum Università di Bologna, Viale Risorgimento 2, \\ I-40136 Bologna, Italy; gianluca.morini3@unibo.it \\ * Correspondence: juergen.brandner@kit.edu; Tel.: +49-721-608-23963
}

Received: 1 March 2019; Accepted: 28 April 2019; Published: 27 May 2019

\begin{abstract}
Pressure is a critical parameter for a large number of industrial processes. The vacuum industry relies on accurate pressure measurement and control. A new compact wireless vacuum sensor was designed and simulated and is presented in this publication. The sensor combines the Pirani principle and Surface Acoustic Waves, and it extends the vacuum sensed range to between $10^{-4} \mathrm{~Pa}$ and $10^{5} \mathrm{~Pa}$ all along a complete wireless operation. A thermal analysis was performed based on gas kinetic theory, aiming to optimize the thermal conductivity and the Knudsen regime of the device. Theoretical analysis and simulation allowed designing the structure of the sensor and its dimensions to ensure the highest sensitivity through the whole sensing range and to build a model that simulates the behavior of the sensor under vacuum. A completely new design and a model simulating the behavior of the sensor from high vacuum to atmospheric pressure were established.
\end{abstract}

Keywords: vacuum sensor; Pirani; surface acoustic waves; wireless sensors

\section{Introduction}

Vacuum technology needs accurate pressure monitoring for different kinds of purposes, including thermal insulation and correct operation of manufacturing systems. Applications might vary from simply monitoring all or parts of a pump down cycle, carefully measuring and controlling a stringent target pressure, or supervising a critical industrial process. In the semiconductor industry, for instance, this enabled dramatic progress on several frontiers of contemporary electronics such as lifetime, precision, and reproducibility of devices that are currently ubiquitous. This capability originates essentially from better production and process control relying on, amongst others, accurate pressure sensors. However, the diversity of pressure ranges and of the required accuracies annihilates the possibility of implementing a single type of gauge that will be of use to all requirements. That is why several types of vacuum sensors based on different operating principles are commercially available operating from as low as $10^{-10} \mathrm{~Pa}$ up to atmospheric pressure and far above. Nonetheless, a cheap sensor that would extend into the high vacuum range and tolerate atmospheric or even higher pressure without switching is highly desirable and not commercially available. Table 1 shows the degree of vacuum with respect to pressure.

Conventional systems for measuring sub-atmospheric pressures include mechanical manometers, ionization gauges, and heat conductivity manometers. Mechanical manometers use some solid 
deflectable objects [1] such as tubes, plates, or diaphragms to measure pressure. The system whose pressure is to be measured is connected to the deflecting object. Any change in pressure causes the object to deflect and this deflection is mechanically amplified using a suitable gear and linkage mechanism, indicated on a calibrated dial. Ionization gauges are vacuum gauges in which the pressure is indicated by the ionization current between two specified electrodes at a prescribed voltage [2].

Table 1. Degree of vacuum with respect to pressure.

\begin{tabular}{cc}
\hline Pressure Range in Pa & Degree of Vacuum \\
\hline $10^{5}$ to $3 \times 10^{3}$ & Low vacuum \\
$3 \times 10^{3}$ to $10^{-1}$ & Medium vacuum \\
$10^{-1}$ to $10^{-4}$ & High vacuum \\
$10^{-4}$ to $10^{-7}$ & Very high vacuum \\
$10^{-7}$ to $10^{-10}$ & Ultra-high vacuum (UHV) \\
$<10^{-10}$ & Extreme-ultrahigh vacuum (EHV or XHV) \\
\hline
\end{tabular}

A heat conductivity pressure gauge is based on a heating element (wire, plate, or chip) inserted inside a chamber that transfers thermal energy to any gas molecules that come into contact with it, and that energy is again transferred to the walls of the chamber. With continuous motion of the gas molecules, a thermal equilibrium is reached as long as the number of gas molecules, i.e., the pressure, remains constant.

If, however, the pressure changes while the wire is being heated from a constant power source, a new thermal equilibrium is reached, and the temperature of the wire changes to indicate the new number of gas molecules that can carry heat away from it.

This means that the temperature of the wire can be used as an indication of the pressure inside the chamber. This is the basic principle of all thermal conductivity gauges to which Pirani sensors belong. They are known for their unsurpassed accuracy in the rough vacuum area. In practice, the heated element is an electrical resistance inserted inside a Wheatstone bridge. Therefore, the temperature variation is transduced into a precise voltage variation.

\section{Theoretical Background}

The Pirani principle operates when a heated element is inserted inside a vacuum chamber. When the Pirani element is supplied with a constant heating power $\mathrm{P}$, it will transfer heat to its surroundings and reach an equilibrium temperature characteristic of the pressure. The Pirani element transfers heat by three means:

- Solid conduction from the Pirani sensor to its carrier; the value of the thermal conductance depends on the geometry of the sensor's carrier and its thermal conductivity.

- Radiation from the sensor's hot surface to the surface of the chamber; its value depends on the emissivity and the exterior surface of the sensor.

- Solid to gas conduction from the sensor to the gas molecules that contact it, which effectively depends on pressure.

The equilibrium equation can be expressed as [3]

$$
P=\left(T-T_{0}\right)\left(G_{r}+G_{c}+G_{g}(p)\right)
$$

where $P$ is the heating power supplied to the sensor, $T$ is the equilibrium temperature, $T_{0}$ is the initial temperature, $G_{r}$ is the radiative thermal conductance, $G_{c}$ is the solid thermal conductance of the sensor's carrier, and $G_{g}$ is the gas conductance.

$$
G_{r}=\frac{\varepsilon \sigma\left(T^{4}-T_{0}^{4}\right) A}{\left(T-T_{0}\right)}
$$


where $\varepsilon$ is the emissivity of the sensor exterior surface, $\sigma$ is the Stefan-Boltzmann constant, and $A$ is the sensor's emitting surface.

In the case where the sensor is suspended by one cylindrical wire, the solid conductance can be expressed as [4]

$$
G_{c}=\frac{\lambda \pi \cdot r^{2}}{l}
$$

where $\lambda$ is the thermal conductivity of the wire material, $r$ is the radius of the wire, and $l$ is the length of the wire. The gas conductance is expressed as follows [3]:

$$
G_{g}(p)=\lambda(p, h) \frac{A}{h}
$$

with $\lambda(p, h)$ the thermal conductivity of the gas at pressure $p$, and $A$ the sensor's surface.

$$
\lambda(p, h)=\lambda\left(p_{0}\right)\left(1+2 \cdot \frac{(2-a) \bar{l}(p)}{a \cdot h} \frac{9.5}{6}\right)^{-1},
$$

where $\lambda\left(p_{0}\right)$ represents the thermal conductivity of the gas at atmospheric pressure, $a$ is the energy accommodation coefficient of the gas molecules, $\bar{l}(p)$ is the pressure-dependent mean free path of the gas molecules, and $h$ is the distance between the sensor's heated surface and the cold ambient surface.

The change in pressure vs. wire temperature remains fairly linear over a pressure range of about $0.01 \mathrm{~Pa}$ to $100 \mathrm{~Pa}$ depending on the wire dimensions. Below this range, heat transfer is dominated by radiation from the wire's surface and conduction from the wire to its carrier $[3,5,6]$. Above this range, heat transfer is ruled by thermal convection [7]. In addition to that, other heat transfer mechanisms, i.e., solid conduction from chip to carrier and radiation, overwhelm the pressure-dependent gas heat transfer. Figure 1 shows the ratio of gas conductance over total conductance versus pressure (obtained from Reference [3]). It can be seen that, below $10^{-2} \mathrm{~Pa}$, the gaseous conductance represents less than $10 \%$ of the total conductance and, above $100 \mathrm{~Pa}$, it represents more than $99 \%$ of the total conductance. Figure 1 shows the actual values of the gas conductance and the total conductance computed from Reference [3]. Figure 2 depicts the gaseous heat transfer over the total heat transfer for the device introduced in Reference [3].

A wide choice of sensors based on the Pirani principle is available in the literature. A list of references is given in Table 2, which also includes the measurement principles and the range of the sensors. The devices are often made using microfabrication and semiconductor technologies $[3,5,8]$. These sensors address different pressure ranges: from two decades of pressure up to seven decades of pressure for one single device [5]. 


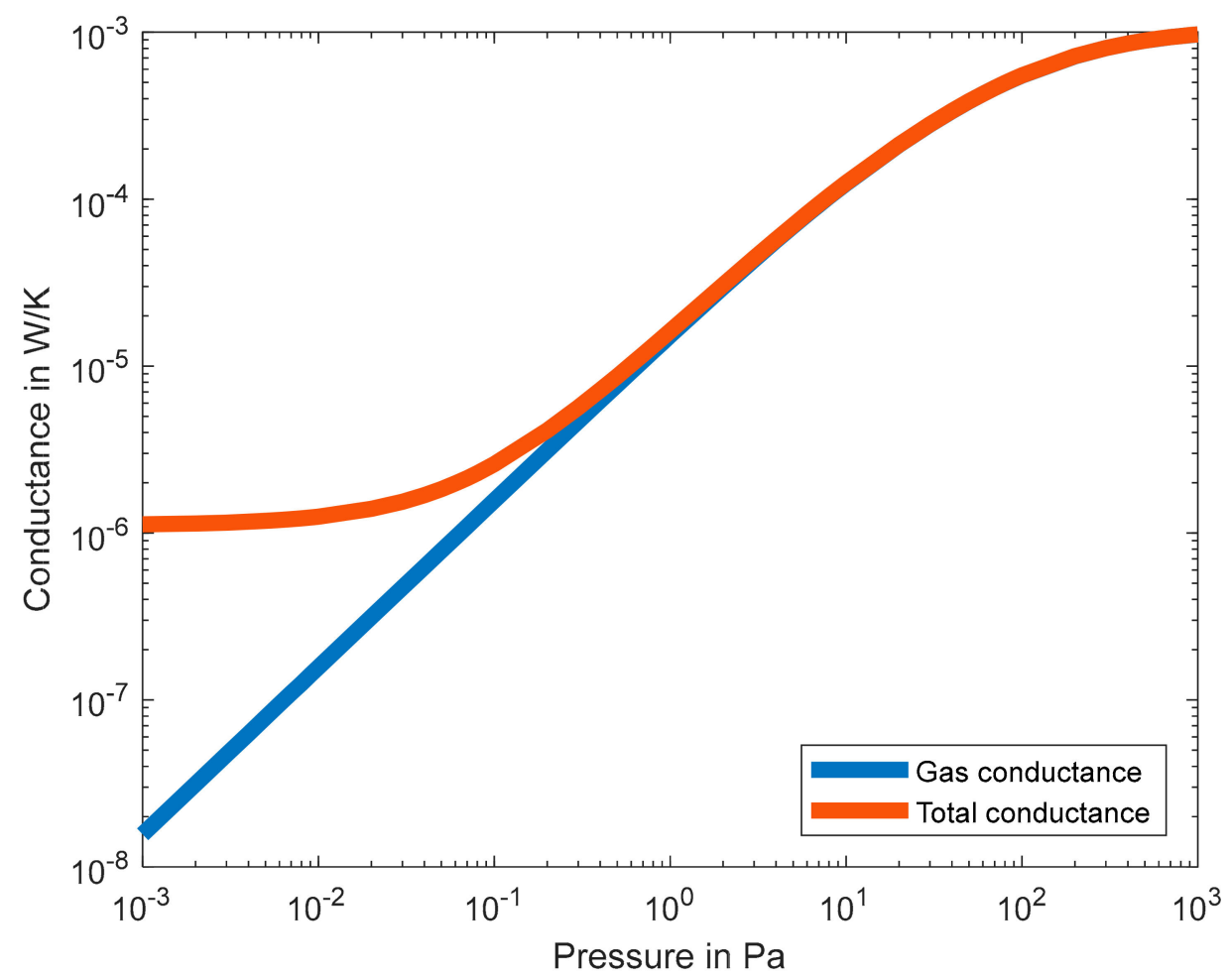

Figure 1. Ratio of gas conductance to total conductance versus pressure computed from Reference [3].

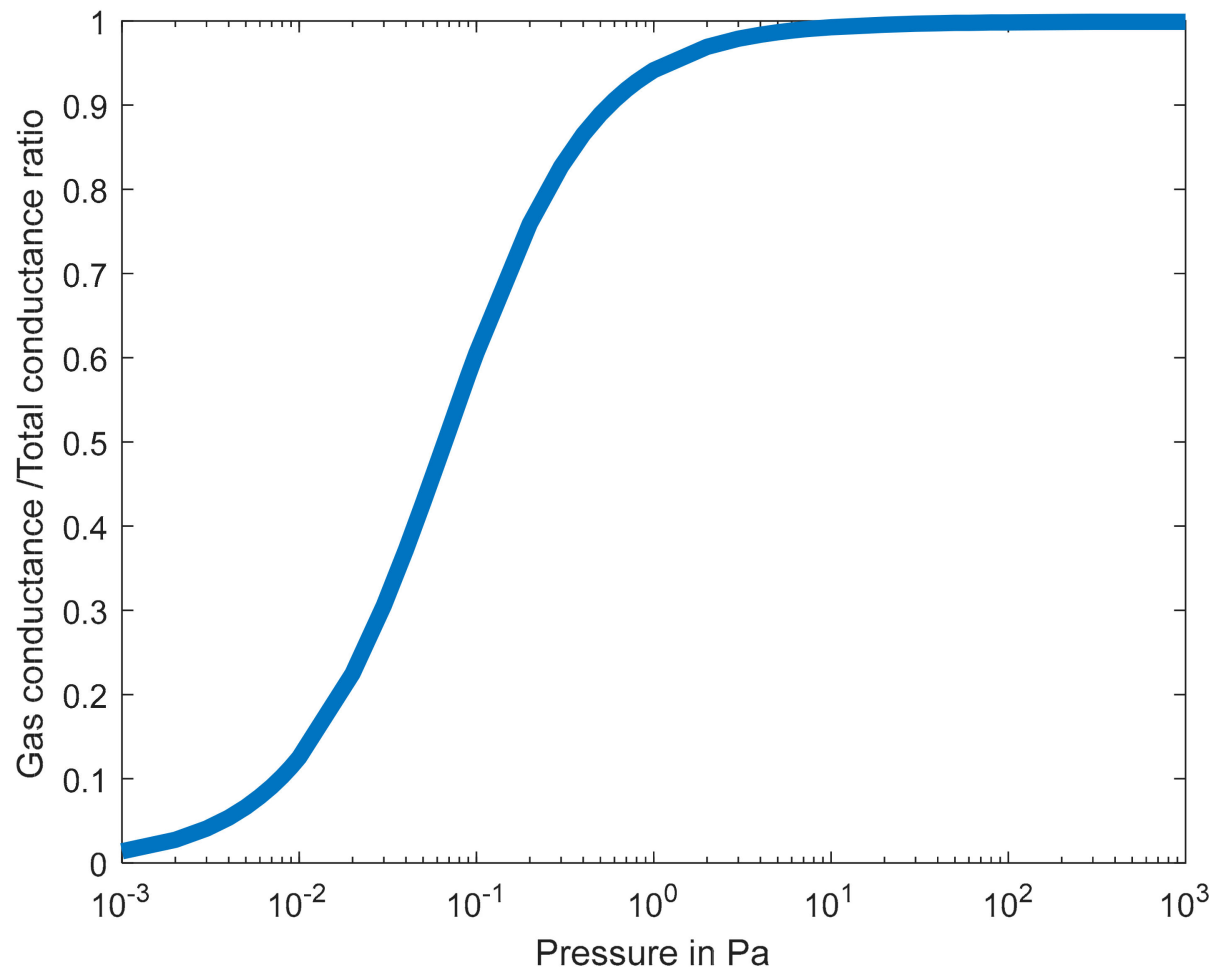

Figure 2. Values of gas conductance and total thermal conductance vs. pressure computed from Reference [3]. 
Table 2. Detection principles and pressure ranges of micro-electro-mechanical system (MEMS) Pirani gauges.

\begin{tabular}{|c|c|c|}
\hline Researcher & Type of Gauge & Pressure Range (Pa) \\
\hline Van Herwaarden and Sarro, 1988 [9] & Heated cantilever combined with thermopile & $0.13-13,300$ \\
\hline Völklein and Schnelle, 1991 [10] & Heated resistor combined with thermopile & $0.13-10$ \\
\hline Piotto et al., 2016 [11] & Heated resistor with thermopile & $0.3-10^{5}$ \\
\hline Mastrangelo and Muller, 1991 [12] & Microbridge & $10-10,000$ \\
\hline Swart et al., 1994 [13] & Microbridge & $13-1.33 \times 10^{5}$ \\
\hline Chae et al., 2004 [14] & Microbridge & $2.6-267$ \\
\hline Moelders et al., 2004 [15] & Microbridge & $1.33-133$ \\
\hline Doms et al., 2005 [16] & Microbridge & $100-10^{5}$ \\
\hline Stark et al., 2005 [17] & Microbridge & $1.33-10^{6}$ \\
\hline Mitchell et al., 2008 [18] & Microbridge & $1.33-10^{5}$ \\
\hline Khosraviani and Leung, 2009 [19] & Microbridge & $13.3-10^{6}$ \\
\hline Li et al., 2009 [20] & Microbridge & $10.6-26,665$ \\
\hline Jiang et al., 2010 [21] & Microbridge & $0.1-1,000$ \\
\hline Chen, 2012 [22] & Microbridge & $133-1.33 \times 10^{5}$ \\
\hline Puers et al., 2002 [23] & Microbridge & $100-10^{7}$ \\
\hline Moutaouekkil et al., 2015 [24] & Microbridge & $1,000-10^{5}$ \\
\hline Mailly et al., 2009 [25] & Microbridge & $20-20,000$ \\
\hline Robinson et al., 1992 [26] & Resistor on dielectric membrane & $10-13,300$ \\
\hline Paul et al., 1994 [27] & Resistor on dielectric membrane & $100-10^{5}$ \\
\hline Weng and Shie, 1994 [5] & Resistor on dielectric membrane & $1.33 \times 10^{-5}-133$ \\
\hline Shie et al., 1995 [28] & Resistor on dielectric membrane & $13.3-1.33 \times 10^{7}$ \\
\hline De Jong et al., 2003 [29] & Resistor on dielectric membrane & $10-20,000$ \\
\hline Zhang et al., 2006 [30] & Resistor on dielectric membrane & $10-10^{5}$ \\
\hline Völklein et al., 2013 [3] & Resistor on dielectric membrane & $1.33 \times 10^{-4}-1332$ \\
\hline Grau et al., 2014 [6] & Resistor on dielectric membrane & $0.13-10^{5}$ \\
\hline Xiao et al., 2011 [7] & Resistor on dielectric membrane & $1-1,000$ \\
\hline Takashima et al., 2008 [31] & Resistor on dielectric membrane & $0.002-10^{5}$ \\
\hline Jeon et al., 2016 [32] & Resistor on dielectric membrane & $0.013-10^{5}$ \\
\hline Paul and Baltes, 1995 [33] & Resistor on dielectric membrane & $100-10^{6}$ \\
\hline Wenzel and Bak, 1998 [34] & Resistor on diaphragm & $10-10^{5}$ \\
\hline Qiu et al., 2009 [35] & Metallic wire & $1-100$ \\
\hline Brun et al., 2012 [36] & Silicon nanowire & $50-10^{5}$ \\
\hline Ghouila-Houri et al., 2017 [37] & Microwire & $10,000-8 \times 10^{5}$ \\
\hline Schelcher et al., 2011 [38] & Ni-microbeam & $3.3-10^{5}$ \\
\hline Wang et al., 2010 [39] & Microplate & $0.1-10^{5}$ \\
\hline Santagata et al., 2011 [40] & Tube-shaped & $0.133-1.33 \times 10^{5}$ \\
\hline Mercier et al., 2012 [41] & $\begin{array}{c}\mathrm{Cr} / \mathrm{Au} \text {-resistor on } \mathrm{LiNbO}_{3} \text {-substrate (SAW } \\
\text { device) }\end{array}$ & $0.001-10^{5}$ \\
\hline
\end{tabular}

However, systematic investigations of Pirani wires identified limits of the process corresponding to saturation due to the pressure dependence of thermal conductivity in high vacuum and close to atmospheric pressure $[3,5,6]$.

A high vacuum process will need to be provided with gauging that follows the pump down cycle from atmospheric pressure through the volume zone and into the dry down zone. A thermal 
conductivity gauge can follow the pressure all the way through the volume zone; however, when the system goes into the dry down zone below about $10^{-2} \mathrm{~Pa}$, where water vapor becomes the predominant residual gas, an ionization gauge becomes necessary. Usually, with the exception of some extended range gauge modifications, these two gauges together can be used to cover the full pump down cycle. This is why many electronic gauge controllers combine both types of gauges in the same unit. For instance, vacuum hybrid sensors such as Pirani Bayard-Alpert and Pirani-Magnetron increase the measurement range from atmospheric to the ultra-high vacuum. Consequently, the revived development of hybrid sensors combining two or more operating principles received much attention recently, since many combined Pirani gauges are commercialized (Canon Cold Cathode Pirani Gauge M-360 CP or BCG 450 from INFICON, for instance). In the present case, two different measurement techniques will be combined, namely the miniaturized Pirani principle and Surface Acoustic Waves (SAW).

Surface acoustic waves are elastic waves that propagate on the surface of piezoelectric crystals [42]. Their propagation frequency and elastic constants are sensitive to the surrounding environment's properties including temperature, pressure, and humidity. SAW devices and sensors are made of a piezoelectric crystal substrate with an interdigitated transducer (IDT) on its surface that converts voltage or other signals to SAW back and forth. An interdigitated transducer consists of a series of etched metallic electrodes whose dimensions determine the properties of the waves that they will generate. SAW devices offer opportunities for wireless operation, as well as self-heating effects $[43,44]$. Having an interdigitated transducer printed on their surface enables them to send and receive waves. Figure 3 shows the principle structure of a SAW device. The SAW IDT is connected to an antenna, generating surface waves when a radio-frequency pulse signal is received. A series of reflectors is available. Reflected waves are received by the transducer, which makes the antenna radiate a return signal with characteristics determined by the reflectors. The reflector configuration can also be used for identifying the device. Many Industrial, Scientific and Medical radio bands are used to operate SAW devices, among which the $2.45-\mathrm{GHz}$ used for the presented device. SAW devices can be operated passively with no need of power supply. Wireless operation is possible because the device can give relatively long delays, preventing overlap between interrogation signal and return signal.

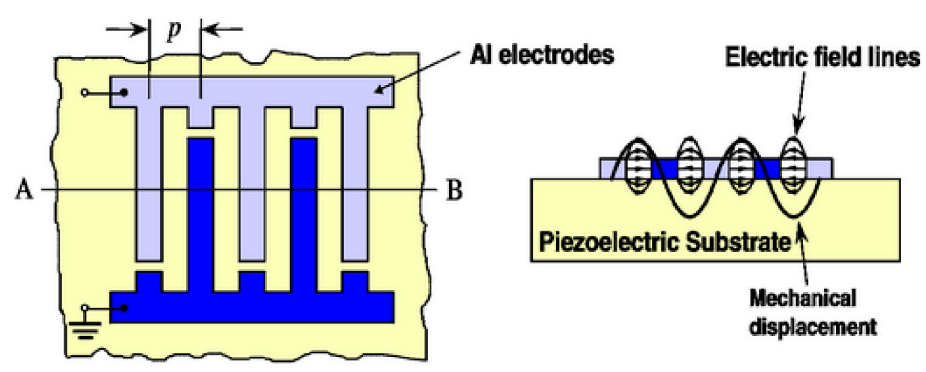

(a)

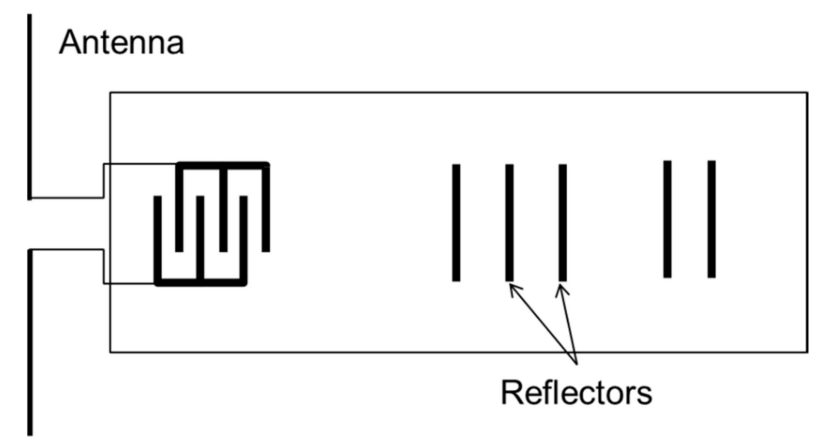

(b)

Figure 3. (a) Schematic structure of a surface acoustic wave (SAW) device. (b) A SAW interdigitated transducer (IDT) with its reflector and antenna. Source Carinthian Tech Research. 
Thanks to their sensitivity to pressure, SAW devices can also be used as pressure sensors. Pressure-induced bending of the piezoelectric crystal membrane generates a change in wave speed that is directly correlated to the pressure. This effect has good sensitivity over a restricted pressure range of one to two decades. Indeed, beyond two decades of pressure, the bending of the crystal will be too large and causes destruction of the crystal [42].

\section{Sensor Description}

Nicolay et al. first had the idea to combine both the Pirani effect and SAW to design a pressure sensor with extended range and sensitivity [45]. After promising first results, wireless heating was added [46]. The device was relatively bulky $(10 \mathrm{~mm} \times 3.1 \mathrm{~mm} \times 8 \mathrm{~mm}$ only for the sensing chip) with a very high response time (more than $5 \mathrm{~min}$ ). In the present work, a similar approach was adopted combining the Pirani principle and SAW.

\subsection{Structure of the Sensor}

The objective of the design work was to develop a sensor able to handle pressures between $10^{-4} \mathrm{~Pa}$ and atmospheric pressure, operating wirelessly and being suitable for microfluidic applications, as well as macroscopic industrial applications. Technical solutions were investigated to design a completely autonomous system fulfilling those requirements. The investigations resulted in the following structure: a $1-\mathrm{cm}^{3}$ polymer cube crossed at its center by a microchannel used for pressure measurement. The heating coil is buried in the bottom part of the core of the sensor, and the interrogation antenna is screen-printed inside the core. Figure 4 shows a schematic of the device.

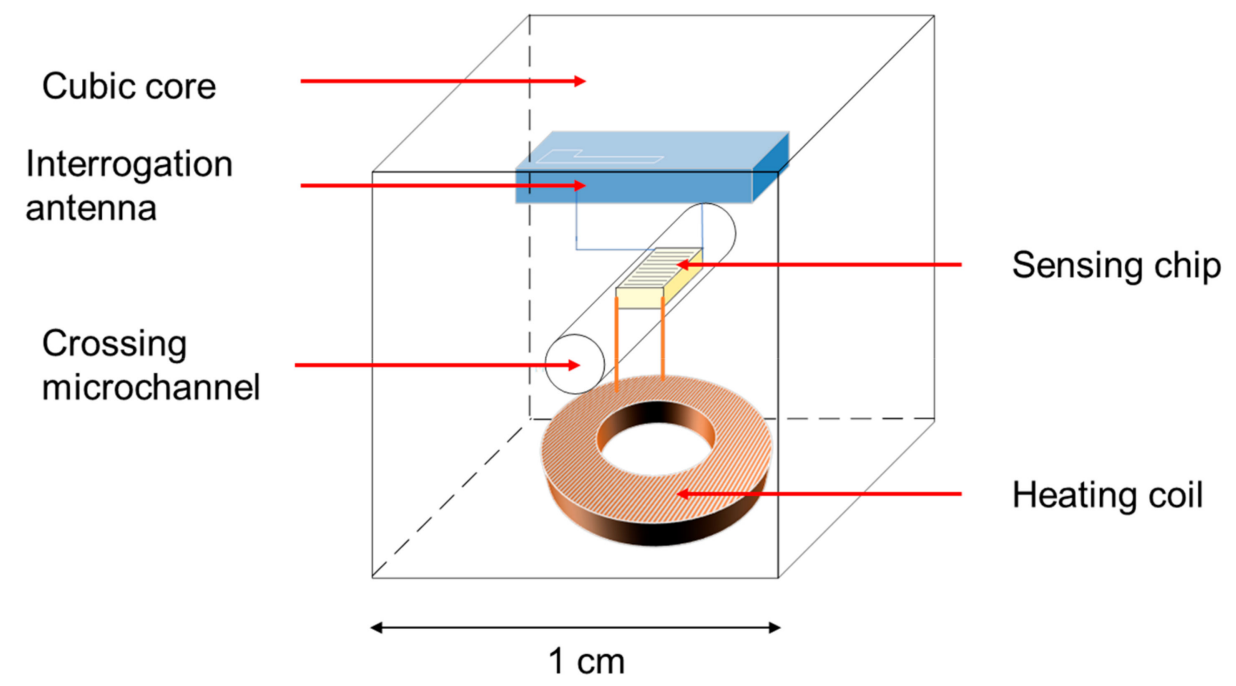

Figure 4. Structure of the wireless vacuum sensor. The design shows a $1 \mathrm{~cm}^{3}$ polymethylmethacrylate (PMMA) cube crossed at its center by a microchannel. The sensing SAW-Pirani chip is inserted inside the microchannel. The heating coil and the interrogation antenna are buried inside the core of the sensor.

\subsection{Components of the Sensor}

The components of the sensor are as follows:

- A polymer housing crossed by the microchannel;

- A SAW-Pirani chip consisting of a block of lithium niobate with an interdigital transducer printed at its surface and a Joule resistance layer at its bottom;

- A heating coil encapsulated by liquid polymer which acts as a seal and controls the temperature;

- An interrogation antenna made with silver screen printing.

A commercial coil was selected that fulfills the requirements of the sensor in terms of power transfer, size, and coupling distance. The chosen coil was the WE-WPCC 760308101216 wireless power 
charging receiver coil manufactured by Wuerth Elektronik (see Figure 5). It can be powered from a distance of up to $2 \mathrm{~cm}$ and delivers power of up to $0.11 \mathrm{~W}$.

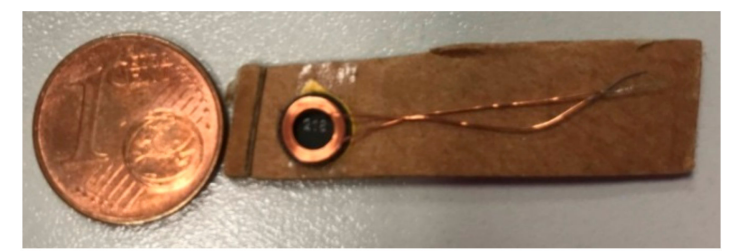

Figure 5. WE-WPCC 760308101216 wireless power charging receiver coil manufactured by Wuerth Elektronik.

The polymer housing is made of polymethylmethacrylate (PMMA). The polymer cube is crossed by a microchannel whose cross-section still needs to be determined. Figure 6 shows potential cross-sections of the channel. The cross-section should be designed on one hand in a way to minimize the physical contact between the chip and the channel, and, on the other hand, to mechanically stabilize and protect the chip. Indeed, the physical contact between the chip and the channel will generate heat leakages that could decrease the sensitivity of the sensor at high vacuum. Thus, the part of the microchannel in physical contact with the cube should be made from an insulating material such as the Code 9658 ceramic.

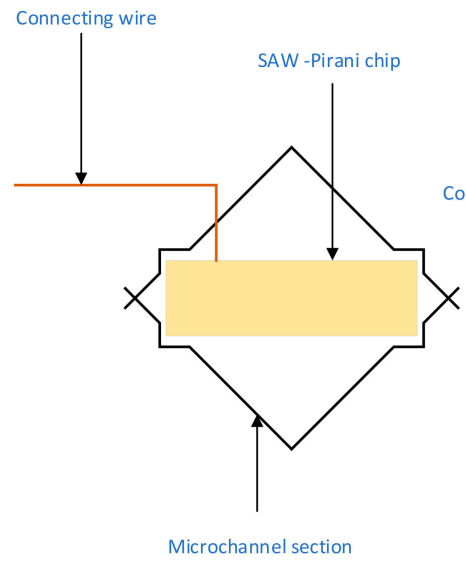

(a)

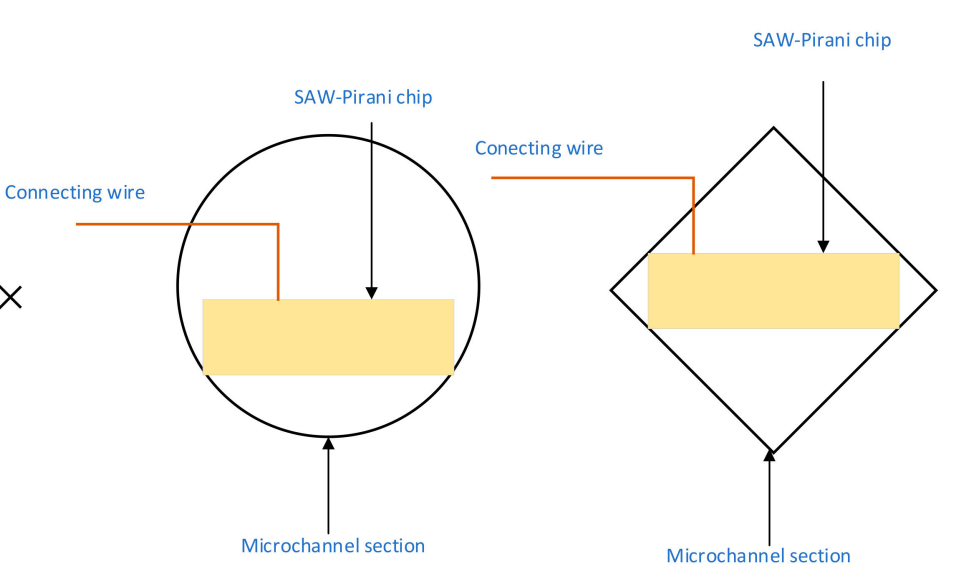

(b) (c)

Figure 6. Different possible cross-sections of the microchannel crossing the sensor: (a) quadratic with holding cavities; (b) circular; (c) quadratic and size-matching.

The dimensions of the chip block were set by Finite Element Method (FEM) heat transfer simulations, as well as the energy required to heat the chip. However, the advocated interdigitated transducer (IDT) on top of the chip was a new design that had to be generated with electron beam lithography. A Joule resistance was added to the chip where the coil delivers its power. Figure 7 shows the design of the IDT. Here, the resistance is surrounding the electrodes, but it can also be manufactured at the bottom of the chip. The structure of the IDT is similar to the one presented in Reference [47], where a SAW chip was used as a temperature sensor operating at $2.45 \mathrm{GHz}$. The corresponding wavelength is $1.3836 \mu \mathrm{m}$, the length of the electrodes is 30 wavelengths, i.e., 41.508 $\mu \mathrm{m}$, and the main IDT contains 22 finger pairs with a metallization ratio of $50 \%$. The thickness of the electrodes is around $50 \mathrm{~nm}$. The first reflector contains five electrodes and is located $2.000 \mathrm{~mm}$ from the main IDT, the second reflector also contains five electrodes and is located $2.0192 \mathrm{~mm}$ from the main IDT, and the third reflector contains 20 electrodes and is located $3.920 \mathrm{~mm}$ from the main IDT. 


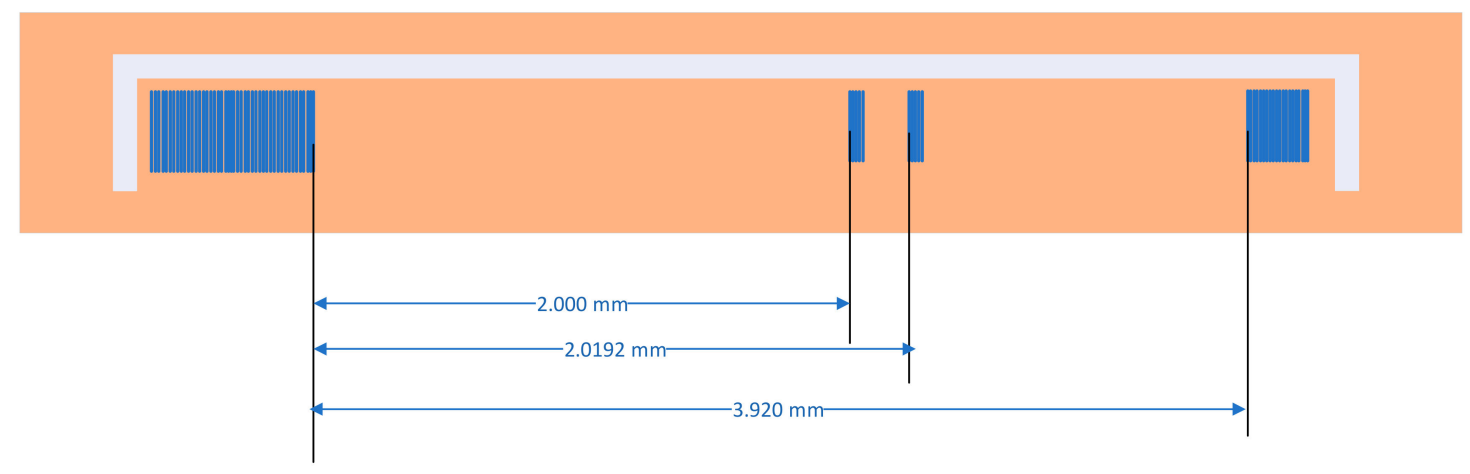

Figure 7. Geometry of the interdigitated transducer generated on top of the chip.

\subsection{Operation of the Sensor}

The sensor is first inserted in a vacuum environment. Then, the SAW chip inside the microchannel is heated via the Joule resistance, receiving energy from the coil. The optimal heating mode of the chip, either pulsed or continuous, still needs to be determined. The interrogation signal is sent to the sensor via the interrogation antenna using a network analyzer. The reflected signal with the modified propagation frequency is received by the same interrogation antenna. The calibration of the sensor allows deducing the pressure from the frequency shift. Figure 8 shows a schematic of the operating protocol of the sensor.

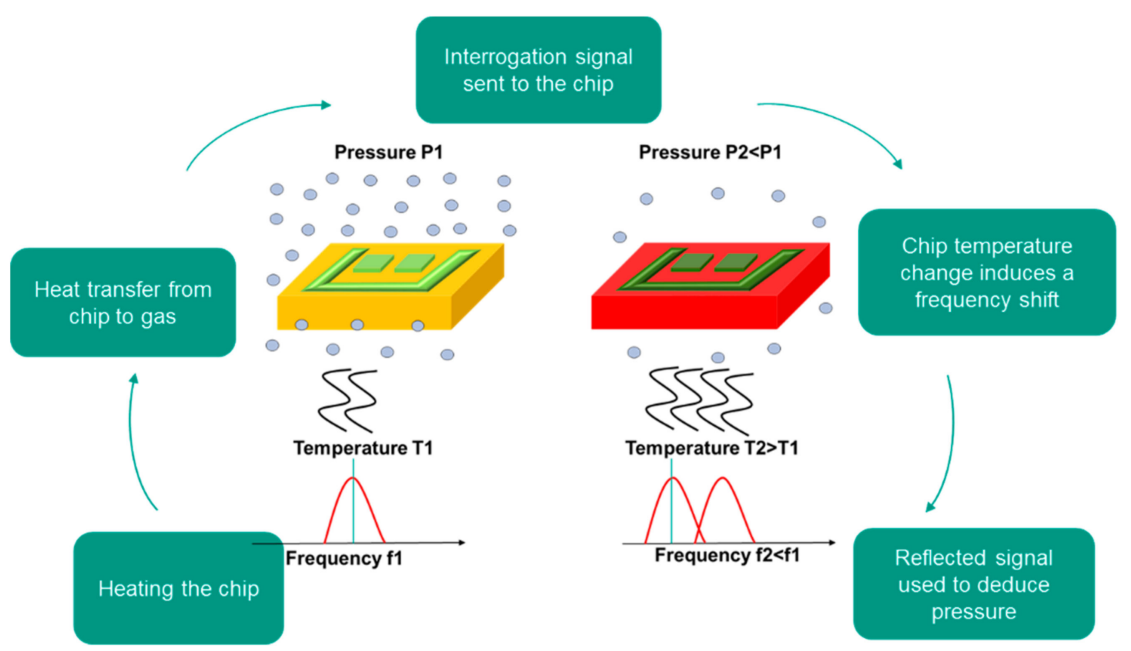

Figure 8. Operating protocol of the sensor.

\subsection{Sensor Simulation}

The sensor designed was simulated using the software COMSOL. The thermal behavior in vacuum and the thermal response were simulated. Using the temperature response of the sensing chip, the corresponding frequency shift was calculated. The calibration curve of the sensor was computed. Figure 9 shows the geometry simulated: a $1-\mathrm{cm}^{3}$ cube crossed at its center by a $600-\mu \mathrm{m}$-diameter microchannel. The chip was inserted inside the microchannel and had a length of $1 \mathrm{~mm}$, a width of $400 \mu \mathrm{m}$, and a thickness of $350 \mu \mathrm{m}$. The pressure was simulated by the variation of the thermal conductivity of the gas. The values used are reported in Table 3. 


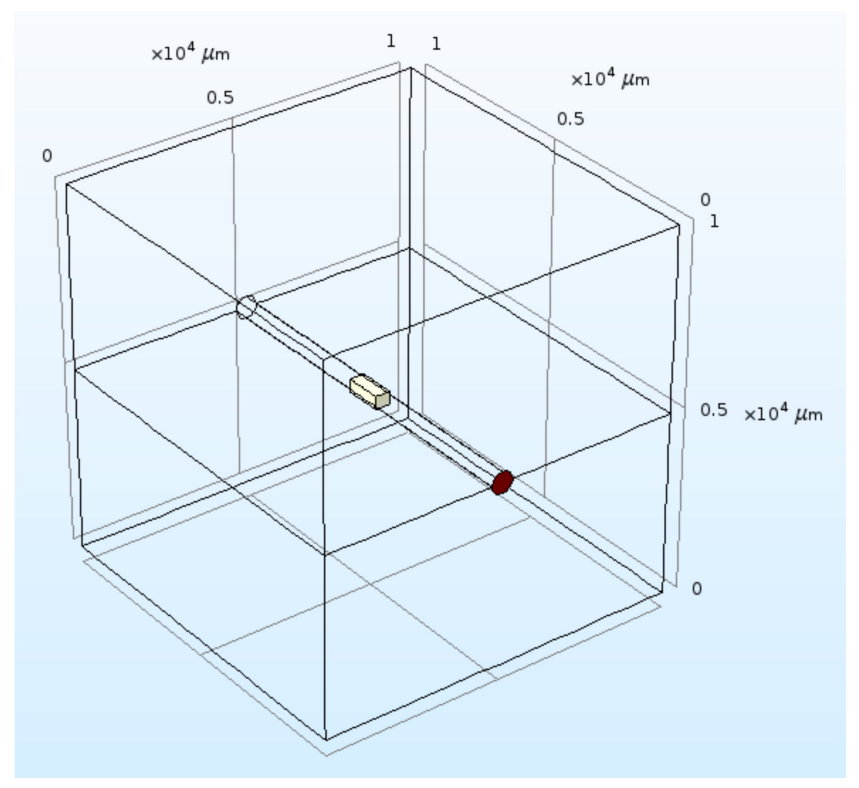

Figure 9. Geometry simulated in COMSOL.

The thermal simulation enabled computing the calibration curve. Figure 10 plots the frequency shift corresponding to each pressure for an initial atmospheric pressure. Table 3 shows the frequency shift at different pressure ranges. The chip is constantly heated from its bottom by introducing a boundary heat source condition of $10,000 \mathrm{~W} / \mathrm{m}^{2}$, which corresponds to a total power of $4 \mathrm{~mW}$, and the steady-state temperature was observed with respect to pressure.

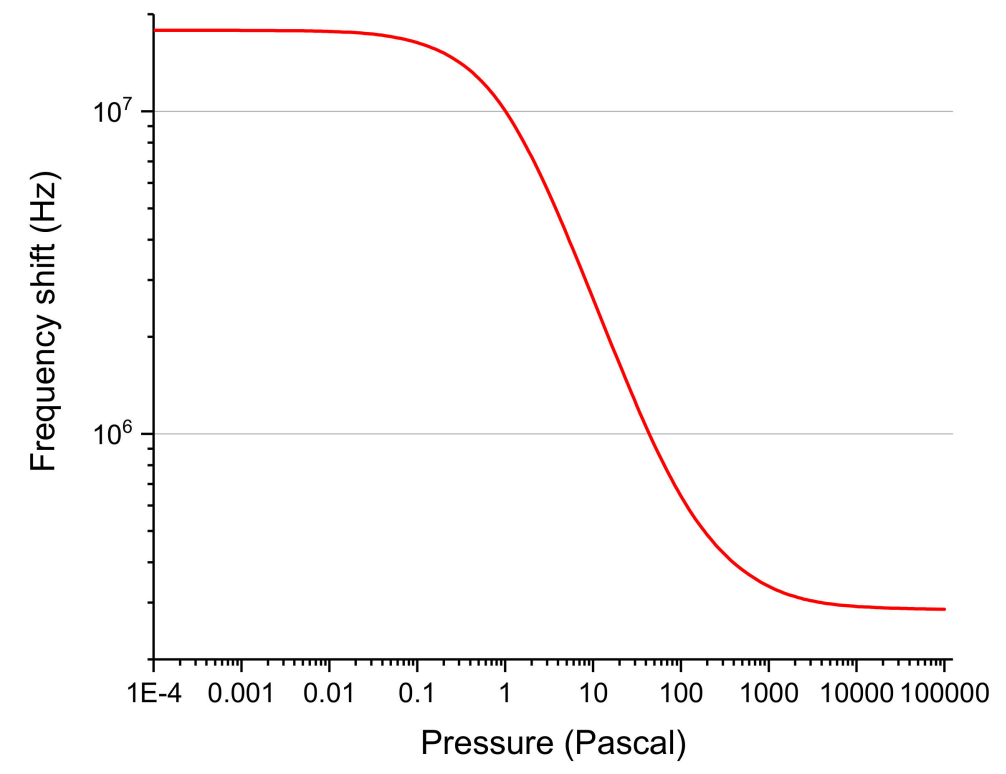

Figure 10. Calibration curve obtained from the simulation.

Table 3. Frequency shift of the sensor at different pressure ranges.

\begin{tabular}{cc}
\hline Pressure Range & Frequency Shift \\
\hline $10^{-4}$ to $10^{-3} \mathrm{~Pa}$ & $15.435 \mathrm{kHz}$ \\
$10^{-3}$ to $10^{-2} \mathrm{~Pa}$ & $152.145 \mathrm{kHz}$ \\
$10^{3}$ to $10^{4} \mathrm{~Pa}$ & $55.125 \mathrm{kHz}$ \\
$10^{4}$ to $10^{5} \mathrm{~Pa}$ & $6.615 \mathrm{kHz}$ \\
\hline
\end{tabular}




\section{Discussion}

\subsection{Thermal Analysis}

A thermal analysis using gas kinetic theory was performed for the present work. Since the sensor measures the pressure of a gas, it was inserted inside a gaseous environment with potential gas flows. To characterize this flow, some figures of merit were used to determine the dimensions of the device. The first figure of merit used was the Knudsen number $K n$.

$$
K n=\frac{\bar{l}(p)}{d}
$$

where $\bar{l}(p)$ is the mean free path of the gas molecules in the conditions of the flow (temperature and pressure), and $d$ is a characteristic dimension of the microchannel, here taken as the hydraulic diameter. The study gas here was nitrogen. The flow regimes were distinguished according to the value of the Knudsen number [48].

- For $K n<0.001$, a continuum flow is taking place and is accurately modeled by the compressible Navier-Stokes equations with classical no-slip boundary conditions.

- For $0.001<K n<0.1$, the flow is a slip flow and the Navier-Stokes equations remain applicable, provided a velocity slip and a temperature jump are taken into account at the walls. Rarefaction effects become sensitive at the walls first.

- For $0.1<K n<10$, the flow is a transition flow. The intermolecular collisions are not yet negligible and have to be taken into account.

- For $K n>10$, the flow is a free molecular flow and the occurrence of intermolecular collisions is negligible compared to the collisions of the gas molecules with the walls.

The second figure of merit needed for this analysis is the thermal conductivity, effectively depending on pressure. As stated in Völklein et al. [3], the thermal conductivity $\lambda(p, h)$ of the gas depends upon the pressure-dependent mean free path of the gas molecules and the distance $h$ between the hot chip and cold channel surface. This model was chosen for its simplicity and reliability, considering the good agreement obtained between simulation and experiments in Reference [3]. The whole sensing process was based on the thermal conductivity of the gas, as given in Equation (7).

$$
\lambda(p, h)=\lambda\left(p_{0}\right)\left(1+2\left(\frac{2-a}{a}\right) \frac{\bar{l}(p)}{h} \frac{9.5}{6}\right)^{-1}
$$

where $\lambda\left(p_{0}\right)$ represents the thermal conductivity of the gas at atmospheric pressure $p_{0}$, and $a$ is the energy accommodation coefficient of the gas molecules at both surfaces ( $a=0.77$ for $N_{2}$ molecules at smooth surfaces). For low pressures in the case of molecular flow, the thermal conductivity $\lambda(p, h)$ becomes directly proportional to $p h$, which is the pressure in Torr multiplied by the characteristic dimension $d$ (see Equation (6)) [3].

$$
\lambda(p, h)=92 \frac{W}{m K} \cdot \frac{p h}{m \text { Torr }} .
$$

In the considered case, the Knudsen number is the ratio between the mean free path of the gas and the characteristic dimension of the system. The mean free path was calculated at a temperature of $300 \mathrm{~K}$, while the pressure was varied between $10^{-4} \mathrm{~Pa}$ and $10^{5} \mathrm{~Pa}$. The Pirani effect is based on the pressure dependence of the thermal conductivity of a gas at the transition and slip flow. The characteristic S-shaped curve of the thermal conductivity vs. pressure shows high sensitivity for pressures between $10^{-2}$ and $10^{2} \mathrm{~Pa}$, with slight variations depending on the dimensions of the sensing element, as can be seen in Figure 9. 
At the edges of this curve, i.e., at high vacuum and near atmospheric pressure, the behavior asymptotically corresponds to saturation. At high vacuum, the collisions between gas molecules and walls are too rare, and the heat transfer between the hot surface and the gas molecule is very small; it cannot be detected by measuring devices. Near atmospheric pressure, the collisions between the walls and the gas molecules are too frequent. This affects the sensitivity of the thermal conductivity to pressure and makes the Pirani effect less efficient. Moreover, near high vacuum, radiative heat transfer between the solid surfaces of the Pirani sensor and solid conduction are ruling the gaseous heat transfer, which makes it more difficult to acquire signals directly linked to the gas pressure.

Both Knudsen number and thermal conductivity were calculated using the mean free path of the gas molecules. It is important to have in mind the orders of magnitude of the mean free path at the different pressure levels. Table 4 shows the values of the mean free path of nitrogen at $300 \mathrm{~K}$ at pressure between $10^{-4} \mathrm{~Pa}$ and $10^{5} \mathrm{~Pa}$. The mean free path was calculated using a hard sphere model presented in Reference [48]. It ranges from $11 \mathrm{~m}$ down to $0.6 \mathrm{~nm}$. In order to achieve a high sensitivity of the Pirani effect, the Knudsen number should be between 0.001 and 10. With a single device, it is not possible to change the size of the gas gap with the pressure; thus, it is important to find a compromise with a dimension that will grant reasonable sensitivity through the whole pressure range.

Table 4. Mean free path of nitrogen at $300 \mathrm{~K}$ for pressures between $10^{-4} \mathrm{~Pa}$ and $10^{5} \mathrm{~Pa}$.

\begin{tabular}{ccc}
\hline Pressure & Mean Free Path & Minimum Size for Knudsen Number below 10 \\
\hline $0.0001 \mathrm{~Pa}$ & $11.4435 \mathrm{~m}$ & $1.14 \mathrm{~m}$ \\
$0.001 \mathrm{~Pa}$ & $1.144 \mathrm{~m}$ & $0.114 \mathrm{~m}$ \\
$0.01 \mathrm{~Pa}$ & $0.1144 \mathrm{~m}$ & $0.01144 \mathrm{~m}$ \\
$0.1 \mathrm{~Pa}$ & $0.0114 \mathrm{~m}$ & $0.00114 \mathrm{~m}$ \\
$1 \mathrm{~Pa}$ & $0.0011 \mathrm{~m}$ & $0.00011 \mathrm{~m}$ \\
$10 \mathrm{~Pa}$ & $1.1444 \times 10^{-4} \mathrm{~m}$ & $1.1444 \times 10^{-5} \mathrm{~m}$ \\
$100 \mathrm{~Pa}$ & $1.1444 \times 10^{-3} \mathrm{~m}$ & $1.1444 \times 10^{-4} \mathrm{~m}$ \\
$1000 \mathrm{~Pa}$ & $1.178 \mu \mathrm{m}$ & $117.8 \mathrm{~nm}$ \\
$10,000 \mathrm{~Pa}$ & $117.8 \mathrm{~nm}$ & $11.78 \mathrm{~nm}$ \\
$50,000 \mathrm{~Pa}$ & $23.6 \mathrm{~nm}$ & $2.36 \mathrm{~nm}$ \\
$100,000 \mathrm{~Pa}$ & $11.8 \mathrm{~nm}$ & $1.18 \mathrm{~nm}$ \\
$101,325 \mathrm{~Pa}$ & $11.6 \mathrm{~nm}$ & $1.16 \mathrm{~nm}$ \\
$200,000 \mathrm{~Pa}$ & $5.9 \mathrm{~nm}$ & $5.9 \AA$ \\
\hline
\end{tabular}

Figure 11 shows the Knudsen regime with respect to the characteristic length of the channel and pressure for nitrogen. As already mentioned, the Pirani effect operates best at the transition and slip flow (green and white zones in the Figure 11), which gives an estimation of the optimum dimensions of the gas gap that need to be used to sense the complete range between high vacuum and atmospheric pressure. A $600 \mu \mathrm{m}$ diameter was chosen to be the characteristic dimension of the microchannel described here for the first simulation so as to increase the sensitivity in high vacuum and for manufacturability concerns.

The structural geometry of the new sensor was simulated using the software COMSOL Multiphysics. A chip with dimensions of $6 \mathrm{~mm}$ length by $400 \mu \mathrm{m}$ width by $350 \mu \mathrm{m}$ thickness was inserted inside a microchannel with a diameter of $600 \mu \mathrm{m}$. The corresponding mean free path and thermal conductivities at $300 \mathrm{~K}$ were computed using Equations (7) and (8) stated above, which led to the values listed in Table 5. For comparison, a second chip was simulated providing $6 \mathrm{~mm}$ length by $400 \mu \mathrm{m}$ width by $200 \mu \mathrm{m}$ thickness. The thermal response of the sensor differed depending on the pressure. Indeed, for the same heating power of the device, the steady-state temperature and the transient response depend on the value of the pressure. This was the case at high vacuum, as well as near atmospheric pressure. 


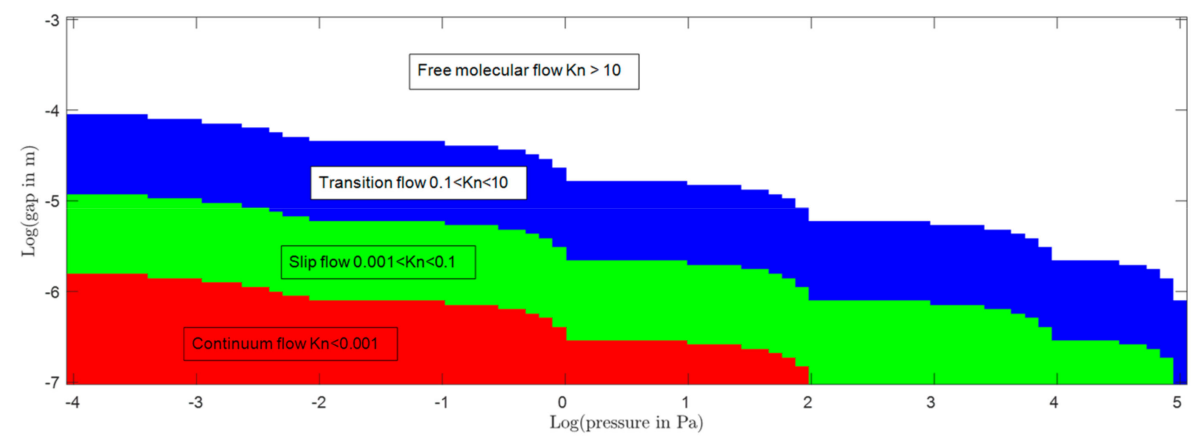

Figure 11. This figure shows the flow regime with respect to the pressure and the size of the gas gap where the sensor chip is located. The red area corresponds to the free molecular flow. The white area corresponds to the transition flow, the green area corresponds to the slip flow, and the blue area corresponds to the continuum flow.

Table 5. Thermal conductivity values used for the simulation.

\begin{tabular}{cc}
\hline Pressure & Thermal Conductivity $(\mathbf{W} / \mathbf{m} / \mathbf{K})$ \\
\hline High Vacuum & \\
\hline $0.0001 \mathrm{~Pa}$ & $4.9 \times 10^{-7}$ \\
$0.0002 \mathrm{~Pa}$ & $9.8 \times 10^{-7}$ \\
$0.0003 \mathrm{~Pa}$ & $1.47 \times 10^{-6}$ \\
$0.0005 \mathrm{~Pa}$ & $2.45 \times 10^{-6}$ \\
$0.001 \mathrm{~Pa}$ & $4.90 \times 10^{-6}$ \\
\hline Near Atmospheric Pressure & \\
\hline $1000 \mathrm{~Pa}$ & 0.0163 \\
$10,000 \mathrm{~Pa}$ & 0.0232 \\
$50,000 \mathrm{~Pa}$ & 0.0245 \\
$100,000 \mathrm{~Pa}$ & 0.0246 \\
$200,000 \mathrm{~Pa}$ & 0.0252 \\
\hline
\end{tabular}

The values given in Table 5 are indicative, since the accommodation coefficients used to compute the thermal conductivity are not known precisely for this surface. However, the real values are expected to have the same order of magnitude, which grants this simulation qualitative relevance concerning the behavior of a real SAW-Pirani chip.

The thermal conductivity analysis and the simulation helped design the complete structure of the sensor shown in Figure 4. Using simulation results, the energy required to heat the chip was predicted to be approximately $24 \mathrm{~mW}$. The simulation allowed determining the dimensions of the chip that provide acceptable sensitivity in high vacuum and atmospheric pressure, i.e., a temperature variation between pressures that can be easily measured wirelessly with the existing equipment, higher or equal to $0.1 \mathrm{~K}$. Packaging and design solutions were chosen based on portability, size, and cost concerns.

\subsection{Wireless Transmission Methods}

Operating a Pirani sensor in a completely wireless way provides major advantages compared to conventional techniques. It is no longer necessary to contact any heating element with wires or to read-out by physical contacts, which avoids leakage in the vacuum range. This makes vacuum-tight throughput systems obsolete for this sensor. Nevertheless, designing the heating element, as well as the read-out element, in a wireless way gives a real novel approach to this sensor type. With this in mind, Surface Acoustic Waves were selected, considering the fact that it is possible to interrogate SAW devices wirelessly for a long time and the technologies are well known. However, heating micro devices wirelessly is still not widespread. Some efforts were taken to find a wireless heating solution 
for the sensor complying with the size restrictions. Table 6 lists different kinds of wireless power supplies already commercially available.

Table 6. Wireless transfer methods available in the market.

\begin{tabular}{|c|c|c|c|c|}
\hline Energy Coupling & $\begin{array}{l}\text { Magnetic } \\
\text { Induction }\end{array}$ & $\begin{array}{c}\text { Magnetic } \\
\text { Resonance }\end{array}$ & $\begin{array}{c}\text { Electrostatic } \\
\text { Coupling }\end{array}$ & $\begin{array}{c}\text { Wireless } \\
\text { Transmission }\end{array}$ \\
\hline Description & $\begin{array}{l}\text { Inductive coupling } \\
\text { between } 2 \text { coils }\end{array}$ & $\begin{array}{l}\text { Coupling between } \\
2 \text { tuned oscillating } \\
\text { circuits }\end{array}$ & $\begin{array}{c}\text { Capacitive } \\
\text { coupling between } 2 \\
\text { electrodes }\end{array}$ & $\begin{array}{l}\text { Reception of radio } \\
\text { waves and } \\
\text { rectification }\end{array}$ \\
\hline Distance & Few $\mathrm{mm}$ to $10 \mathrm{~cm}$ & Few $\mathrm{cm}$ to $\mathrm{m}$ & Few $\mathrm{mm}$ to few $\mathrm{cm}$ & Up to a few m \\
\hline $\begin{array}{c}\text { Transferable } \\
\text { power }\end{array}$ & $\begin{array}{c}\text { Few } \mathrm{W} \text { to several } \\
\mathrm{kW}\end{array}$ & Few $\mathrm{W}$ to $\mathrm{kW}$ & $\begin{array}{c}\text { Few } W \text { to few } 100 \mathrm{~s} \\
\text { of } W\end{array}$ & $1 \mathrm{~W} \max$ \\
\hline $\begin{array}{l}\text { Electrical } \\
\text { efficiency }\end{array}$ & $\begin{array}{c}70 \% \text { to } 90 \% \text { heat } \\
\text { loss }\end{array}$ & $\begin{array}{l}40 \% \text { to } 60 \% \\
\text { residual heat }\end{array}$ & $\begin{array}{c}60 \% \text { to } 90 \% \text { heat } \\
\text { loss }\end{array}$ & \\
\hline Frequency & $10 \mathrm{kHz}$ & $\begin{array}{c}\text { Few } 100 \mathrm{kHz} \text { up to } \\
\mathrm{MHz}\end{array}$ & $\begin{array}{c}\text { Few } 100 \mathrm{kHz} \text { to few } \\
\mathrm{MHz}\end{array}$ & $\begin{array}{l}\text { Frequencies up to } \\
\text { microwaves }\end{array}$ \\
\hline
\end{tabular}

\subsection{Choice of the Interrogation Frequency and Interrogation Antenna}

While wireless interrogation can be achieved at any readout frequency, there is only a distinct number of radio-frequency (RF) bands which are free for industrial-scientific medical (ISM) applications. Here, the ISM band from $2.4 \mathrm{GHz}$ to $2.4835 \mathrm{GHz}$ proved to be most suitable, as it has an adequate bandwidth $(83.5 \mathrm{MHz})$ and an almost worldwide geographical license. At the same time, it allows a read-out at a distance of several meters. At this frequency, the radio-frequency wavelength is about $13.5 \mathrm{~cm}$, thus permitting the use of simple and small antennas, e.g., dipoles, and slot or patch antennas, favorably for the transponder part. To achieve higher precision, the frequency of $2.45 \mathrm{GHz}$ was chosen to allow a high frequency shift which is more easily detectable especially at low pressures. The stated precision of lithium niobate SAW devices is 70 to $90 \mathrm{ppm} / \mathrm{K}$ [49] and up to $100 \mathrm{ppm} / \mathrm{K}$, which represents 30,310 to $38,970 \mathrm{~Hz} / \mathrm{K}$ at $433 \mathrm{MHz}$ and 171,500 to $220,500 \mathrm{~Hz} / \mathrm{K}$ at $2.45 \mathrm{GHz}$. After the choice of the interrogation frequency, the corresponding antenna has to be designed and inserted inside the cube. COMSOL will be used to optimize the shape, size, and position of the antenna inside the cube.

\section{Conclusions}

The vacuum sensor presented here is new in the sense that it is extending the sensing range, while operating completely wirelessly. The performance was not tested in real-world applications, but it contains innovations compared to conventional Pirani wires or SAW sensors or even the SAW-Pirani sensors presented in the literature. The prototype still needs to be assembled and tested, which will state the actual performance of the sensor. Previous work on SAW-Pirani sensors was studied, and design directions such as the reduction of the thickness of the chip, the increase of the surface-to-volume ratio, and the increase of the operating frequency to obtain a higher thermal sensitivity of the chip were taken into account.

This work presents an innovative compact wireless SAW-Pirani sensor for microscopic and macroscopic applications. The combination of both surface acoustic waves and heat transfer in gases allows extending the sensing range of a vacuum sensor and to operate this sensor wirelessly, which can be advantageous in vacuum technology. The results given by simulation predict a sensitivity of $0.1 \mathrm{~K}$ for a pressure variation of $10^{-4} \mathrm{~Pa}$, which could easily be detected by the available instruments in the lab. Furthermore, it is expected that further investigations concerning the modus operandi of the sensor will improve the sensitivity of the sensor in high vacuum and close to atmospheric pressure. For instance, applying pulsed heating instead of continuous heating could increase the sensitivity of the resonance frequency of the sensor to the pressure through the whole target range. A prototype of the described sensor design is currently being assembled and tested. The best modus operandi of the sensor still needs to be determined. 
Further work, therefore, includes the investigation of the transformation of SAW signal in vacuum and its dependence on pressure. To support that, Sharipov et al. reported interaction between acoustic waves and thermal waves in vacuum [50].

Author Contributions: Conceptualization, S.T., P.N. and M.R.; methodolgy, S.T.; simulation and formal analysis, S.T. writing-original draft preparation, S.T.; writing-review and editing, J.J.B., J.G.K. and G.L.M., supervision, J.J.B., project administration, J.J.B., funding acquisition, J.J.B.

Funding: The authors would like to acknowledge the financial support provided by the EU network program H2020 under Grant MIGRATE No. 643095.

Conflicts of Interest: The authors declare no conflicts of interest.

\section{References}

1. Figliola, R.S.; Beasley, D.E. Theory and design for mechanical measurements. Meas. Sci. Technol. 1996, 12, 1743. [CrossRef]

2. Pace, E.L. Scientific foundations of vacuum technique (Dushman, Saul). J. Chem. Educ. 1962, 39, A606. [CrossRef]

3. Völklein, F.; Grau, M.; Meier, A.; Hemer, G.; Breuer, L.; Woias, P. Optimized MEMS Pirani sensor with increased pressure measurement sensitivity in the fine and high vacuum regime. J. Vac. Sci. Technol. A Vac. Surf. Film. 2013, 31, 061604. [CrossRef]

4. Jitschin, W.; Ludwig, S. Dynamical behaviour of the Pirani sensor. Vacuum 2004, 75, 169-176. [CrossRef]

5. Weng, P.K.; Shie, J.S. Micro-Pirani vacuum gauge. Rev. Sci. Instrum. 1994, 65, 492-499. [CrossRef]

6. Grau, M.; Völklein, F.; Meier, A.; Kunz, C.; Kaufmann, I.; Woias, P. Optimized MEMS Pirani sensor with increased pressure measurement sensitivity in the fine and rough vacuum regimes. J. Vac. Sci. Technol. A Vac. Surf. Film. 2014, 33, 021601. [CrossRef]

7. Xiao, B.; Dong, T.; Halvorsen, E.; Yang, Z.; Zhang, Y.; Hoivik, N.; Gu, D.; Tran, N.M.; Jakobsen, H. Integrated micro Pirani gauge based hermetical package monitoring for uncooled VOxbolometer FPAs. Microsyst. Technol. 2011, 17, 115-125. [CrossRef]

8. Völklein, F.; Meier, A. Microstructured vacuum gauges and their future perspectives. Vacuum 2007, 82, 420-430. [CrossRef]

9. Van Herwaarden, A.W.; Sarro, P.M. Performance of integrated thermopile vacuum sensors. J. Phys. E Sci. Instrum. 1988, 21, 1162-1167. [CrossRef]

10. Völklein, F.; Schnelle, W. A vacuum microsensor for the low-vacuum range. Sens. Mater. 1991, 3, 41-48.

11. Piotto, M.; Del Cesta, S.; Bruschi, P. A Compact CMOS Compatible micro-Pirani Vacuum Sensor with Wide Operating Range and Low Power Consumption. Procedia Eng. 2016, 168, 766-769. [CrossRef]

12. Mastrangelo, C.H.; Muller, R.S. Microfabricated thermal absolute-pressure sensor with on-chip digital front-end processor. IEEE J. Solid-State Circuits 1991, 26, 1998-2007. [CrossRef]

13. Swart, N.R.; Nathan, A. An integrated CMOS polysilicon coil-based micro-Pirani gauge with high heat transfer efficiency. In Proceedings of the 1994 IEEE International Electron Devices Meeting, San Francisco, CA, USA, 11-14 December 1994; pp. 135-138.

14. Chae, J.; Stark, B.H.; Najafi, K. A micromachined Pirani gauge with dual heat sinks. In Proceedings of the 17th IEEE International Conference on Micro Electro Mechanical Systems. Maastricht MEMS 2004 Technical Digest, Maastricht, The Netherlands, 25-29 January 2004; pp. 532-535.

15. Moelders, N.; Daly, J.T.; Greenwald, A.C.; Johnson, E.A.; McNeal, M.P.; Patel, R.; Pralle, M.U.; Puscasu, I. Micro and Nanosystems Symposium, Boston 2004; Society, M.R., Ed.; MRS: Boston, MA, USA, 2004; p. 211.

16. Doms, M.; Bekesch, A.; Mueller, J. A microfabricated Pirani pressure sensor operating near atmospheric pressure. J. Micromech. Microeng. 2005, 15, 1504-1510. [CrossRef]

17. Stark, B.H.; Junseok, C.; Kuo, A.; Oliver, A.; Khalil, N. A high-performance surface-micromachined Pirani gauge in SUMMIT V/spl trade. In Proceedings of the 18th IEEE International Conference on Micro Electro Mechanical Systems, 2005. MEMS 2005, Miami Beach, FL, USA, 30 January-3 February 2005; pp. 295-298.

18. Mitchell, J.; Lahiji, G.R.; Najafi, K. An Improved Performance Poly-Si Pirani Vacuum Gauge Using Heat-Distributing Structural Supports. J. Microelectromech. Syst. 2008, 17, 93-102. [CrossRef] 
19. Khosraviani, K.; Leung, A.M. The nanogap Pirani-A pressure sensor with superior linearity in an atmospheric pressure range. J. Micromech. Microeng. 2009, 19, 045007. [CrossRef]

20. Li, Q.; Goosen, J.F.L.; van Beek, J.T.M.; van Keulen, F. A novel SOI Pirani sensor with triple heat sinks. Procedia Chem. 2009, 1, 160-163. [CrossRef]

21. Jiang, W.; Wang, X.; Zhang, J. A single crystal silicon micro-Pirani vacuum gauge with high aspect ratio structure. Sens. Actuators A Phys. 2010, 163, 159-163. [CrossRef]

22. Chen, C. Characterization of Gas Conductance of a Thermal Device with a V-Groove Cavity. IEEE Electron Device Lett. 2012, 33, 275-277. [CrossRef]

23. Puers, R.; Reyntjens, S.; De Bruyker, D. The NanoPirani-An extremely miniaturized pressure sensor fabricated by focused ion beam rapid prototyping. Sens. Actuators A Phys. 2002, 97-98, 208-214. [CrossRef]

24. Moutaouekkil, M.; Talbi, A.; Viard, R.; Gerbedoen, J.C.; Okada, E.; Elmazria, O.; Preobrazhensky, V.; Merlen, A.; Pernod, P.; Joint International Laboratory LIA LICS/LEMAC. Elaboration of a Novel Design Pirani Pressure Sensor for High Dynamic Range Operation and Fast Response Time. Procedia Eng. 2015, 120, 225-228. [CrossRef]

25. Mailly, F.; Dumas, N.; Pous, N.; Latorre, L.; Garel, O.; Martincic, E.; Verjus, F.; Pellet, C.; Dufour-Gergam, E.; Nouet, P. Pirani pressure sensor for smart wafer-level packaging. Sens. Actuators A Phys. 2009, 156, 201-207. [CrossRef]

26. Robinson, A.M.; Haswell, P.; Lawson, R.P.W.; Parameswaran, M. A thermal conductivity microstructural pressure sensor fabricated in standard complementary metal-oxide semiconductor. Rev. Sci. Instrum. 1992, 63, 2026-2029. [CrossRef]

27. Paul, O.; Haberli, A.; Malcovati, P.; Baltes, H. Novel integrated thermal pressure gauge and read-out circuit by CMOS IC technology. In Proceedings of the 1994 IEEE International Electron Devices Meeting, San Francisco, CA, USA, 11-14 December 1994; pp. 131-134.

28. Shie, J.S.; Chou, B.C.S.; Chen, Y.M. High performance Pirani vacuum gauge. J. Vac. Sci. Technol. A 1995, 13, 2972-2979. [CrossRef]

29. Jong, B.R.D.; Bula, W.P.; Zalewski, D.; Baar, J.J.V.; Wiegerink, R.J. Pirani pressure sensor with distributed temperature measurement. In Proceedings of the SENSORS, 2003 IEEE, Toronto, ON, Canada, 22-24 October 2003; Volume 1, pp. 718-722.

30. Zhang, F.T.; Tang, Z.; Yu, J.; Jin, R.C. A micro-Pirani vacuum gauge based on micro-hotplate technology. Sens. Actuators A Phys. 2006, 126, 300-305. [CrossRef]

31. Takashima, N.; Kimura, M. Investigation on the Thin Film Pirani Vacuum Sensor Using A Constant Voltage Drive-Mode Diode-Heater. IEEJ Trans. Sens. Micromach. 2008, 128, 209-213. [CrossRef]

32. Jeon, G.-J.; Kim, W.Y.; Shim, H.B.; Lee, H.C. Nanoporous Pirani sensor based on anodic aluminum oxide. Appl. Phys. Lett. 2016, 109, 123505. [CrossRef]

33. Paul, O.; Baltes, H. Novel fully CMOS-compatible vacuum sensor. Sens. Actuators A Phys. 1995, 46, $143-146$. [CrossRef]

34. Wenzel, O.; Bak, C.K. The Micro Pirani ${ }^{\mathrm{TM}}$ : A solid-state vacuum gauge with wide range. Vak. Forsch. Prax. 1998, 10, 298-301. [CrossRef]

35. Qiu, Y.; Zhao, L.; Jin, Y. A novel micro pirani gauge with mono-wire sensing unit for microsystem application. In Proceedings of the 2009 International Conference on Electronic Packaging Technology \& High Density Packaging, Beijing, China, 10-13 August 2009; pp. 467-470.

36. Brun, T.; Mercier, D.; Koumela, A.; Marcoux, C.; Duraffourg, L. Silicon nanowire based Pirani sensor for vacuum measurements. Appl. Phys. Lett. 2012, 101, 183506. [CrossRef]

37. Ghouila-Houri, C.; Sindjui, R.; Moutaouekkil, M.; Elmazria, O.; Gallas, Q.; Garnier, E.; Merlen, A.; Viard, R.; Talbi, A.; Pernod, P. Nanogap Pirani Sensor Operating in Constant Temperature Mode for Near Atmospheric Pressure Measurements. Proceedings 2017, 1, 377. [CrossRef]

38. Schelcher, G.; Fabbri, F.; Lefeuvre, E.; Brault, S.; Coste, P.; Dufour-Gergam, E.; Parrain, F. Modeling and characterization of MicroPirani vacuum gauges manufactured by a low-temperature film transfer process. J. Microelectromech. Syst. 2011, 20, 1184-1191. [CrossRef]

39. Wang, X.; Liu, C.; Zhang, Z.; Liu, S.; Luo, X. A micro-machined Pirani gauge for vacuum measurement of ultra-small sized vacuum packaging. Sens. Actuators A Phys. 2010, 161, 108-113. [CrossRef]

40. Santagata, F.; Iervolino, E.; Mele, L.; van Herwaarden, A.W.; Creemer, J.F.; Sarro, P.M. An analytical model and verification for MEMS Pirani gauges. J. Micromech. Microeng. 2011, 21, 115007. [CrossRef] 
41. Mercier, D.; Bordel, G.; Brunet-Manquat, P.; Verrun, S.; Elmazria, O.; Sarry, F.; Belgacem, B.; Bounoua, J. Characterization of a SAW-Pirani vacuum sensor for two different operating modes. Sens. Actuators A Phys. 2012, 188, 41-47. [CrossRef]

42. Rokhlin, S.I.; Kornblit, L.; Gorodetsky, G. Surface acoustic wave pressure transducers and accelerometers. Prog. Aerosp. Sci. 1984, 21,1-31. [CrossRef]

43. Singh, K.J.; Elmazria, O.; Sarry, F.; Nicolay, P.; Ghoumid, K.; Belgacem, B.; Mercier, D.; Bounouar, J. Enhanced Sensitivity of SAW-Based Pirani Vacuum Pressure Sensor. IEEE Sens. J. 2011, 11, 1458-1464. [CrossRef]

44. Joshi, S.G. Use of a surface-acoustic-wave (SAW) device to measure gas flow. IEEE Trans. Instrum. Meas. 1989, 38, 824-826. [CrossRef]

45. Nicolay, P. Surface Acoustic Wave sensors: Applications for the Measurement of Low Pressures and High Temperatures. Ph.D. Thesis, Université Henri Poincaré, Nancy, France, 2007.

46. Nicolay, P.; Lenzhofer, M. A wireless and passive low-pressure sensor. Sensors 2014, 14, 3065-3076. [CrossRef]

47. Fu, C.; Ke, Y.; Li, M.; Luo, J.; Li, H.; Liang, G.; Fan, P. Design and Implementation of 2.45 GHz Passive SAW Temperature Sensors with BPSK Coded RFID Configuration. Sensors 2017, 17, 1849. [CrossRef]

48. Kandlikar, S.; Garimella, S.; Li, D.; Colin, S.; King, M.R. Heat Transfer and Fluid Flow in Minichannels and Microchannels; Elsevier Science: Oxford, UK, 2006.

49. Royer, D.; Dieulesaint, E. Ondes Élastiques Dans les Solides; Masson: Paris, France, 1996; p. 321.

50. Kalempa, D.; Sharipov, F. Numerical modelling of thermoacoustic waves in a rarefied gas confined between coaxial cylinders. Vacuum 2014, 109, 326-332. [CrossRef]

(C) 2019 by the authors. Licensee MDPI, Basel, Switzerland. This article is an open access article distributed under the terms and conditions of the Creative Commons Attribution (CC BY) license (http://creativecommons.org/licenses/by/4.0/). 